\title{
ECO-FRIENDLY MANAGEMENT OF HARMFUL COLONIZATION OF STRIPED MEALYBUG (FERRISIA VIRGATA) OVER PLANTS BY USING HERBAL PESTICIDE
}

\author{
Akanksha Tripathi \\ Department of Zoology \\ M.L.K. P.G. College, Balrampur (U.P.), India
}

Corresponding author: akt.zoology@gmail.com

Article Info:

Research Article Received

15.02.2021

Reviewed

25.03.2021

Accepted

08.04.2021

\begin{abstract}
The infestation of striped mealybug (Ferrisia virgata) is common in orchards causing large scale harms to fruit quality as well as quantity. A water-based insecticide was not proved effective to control the mealybugs due to the presence of waxy outer coating. 30 percent ethyl alcohol was added in order to make the herbal preparations effective. Clerodendron sp., Cymbopogon citratus, Pongamia pinnata and Azadirachta indica extracts were tested for management of Ferrisia virgata. A 25\% concentration of Cymbopogon leaf extract was found as a most effective eco-friendly management tool and safe herbal pesticide having no harmful effect over the experimental plants as well as on other plants.
\end{abstract}

Keywords: Eco-friendly Management, Ferrisia virgata, Herbal Pesticide, Hibiscus rosa sinensis.

\section{INTRODUCTION}

Mealybugs such as Ferrisia virgata badly affect the growth and productivity of plants through sap feeding (Dreistadt 2001; Franco et al., 2009). Sometimes infestation of these insects may be fatal to the whole plant or even whole orchard. They generally have waxy coatings over their adults that make mealybugs resistant against general pesticides. Mealybugs have overlapping generations; therefore, multiple applications of broad-spectrum pesticides are required (Ammar et al.,1979). Sometimes pesticidal applications have adverse effects on beneficial insects than over the target mealybugs. Generally, some fire ant species symbiotically live with mealybugs for honeydew produced by mealybugs, which additionally can worsen the infestation management (Cheng et al., 2015).

Ferrisia virgata is called a striped mealybug because of its two dark, dorsal stripes that run lengthwise down its body. These stripes are visible on the coccid insect cuticle through vacant patches within the waxy covering (Fig.1). Length of the female is close to 2.0-4.5 millimetre (Kaydan and Gullan, 2012). The other distinguishing features of the striped coccid insect are the presence of two posterior waxy tails or tassels that is half-length of its body. The presence of crystalline hair-like rods extending laterally from the body, and there is also an absence of associated ovisac (egg sac) (Ferris, 1950).

The insecticides impart a very good control of the pest but these are directly or indirectly harmful to mankind. The bitter experience of the use of chemical insecticides and presence of rich flora in our country attract the attention of scientists to develop effective and economic control methods 


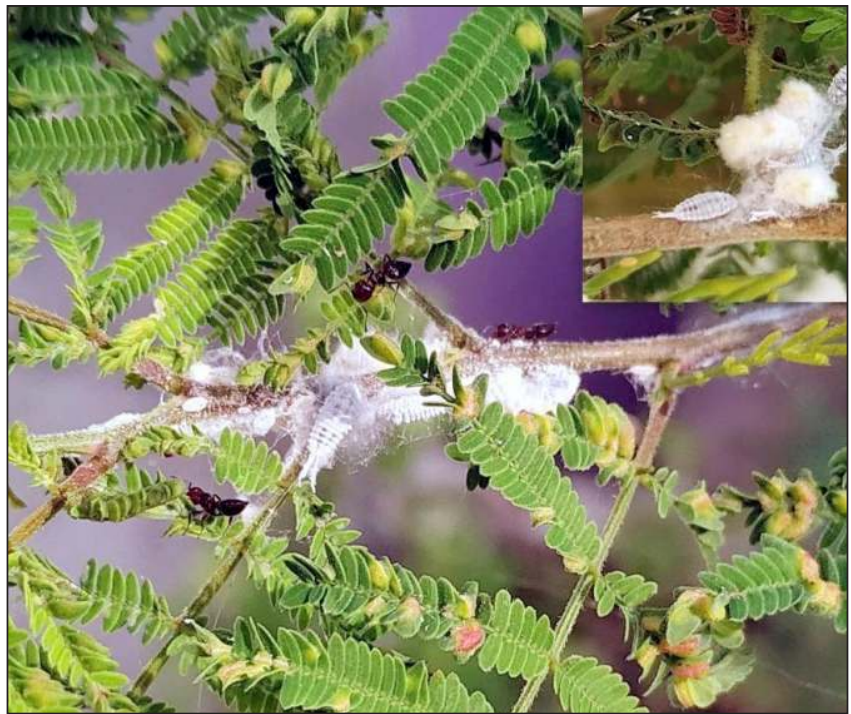

Fig.1: Striped mealybugs (Ferrisia virgata) and their symbiotic associates, fire ants over a Shami plant.

by exploring the botanical insecticides. So, it has become necessary to evolve control measures, which may be selective in action and relatively harmless to nontarget organisms and human beings. Thus, insecticides of plant origin are preferred over chemical insecticides because of their nontoxic nature to human beings. Herbal pesticides and other agricultural applications are the need of the hour because synthetic pesticides have very hazardous implications over the flora and fauna including fishes all over the world (Prakash and Verma, 2014 \& 2020; Verma and Prakash, 2018; Kaur and Mishra, 2019). These synthetic pesticides pollute our food, water, soil, air and badly affect the ecological balance that in turn influences the widespread biodiversity and human survival (Ashok, 2017 \& 2018).

The herbal pesticides are eco-friendly alternative for insect-pest management solutions, which are cost effective, easily available and have almost no adverse effect over useful soil inhabiting insects (Williams and Watson,1988). However, broadspectrum herbal pesticides are not easily available commercially and their preparation at domestic level requires some basic technical knowledge.

\section{MATERIALS AND METHODS}

The experiment was carried out in the Department of Zoology, MLK PG College,
Balrampur (U.P.), India in the insect-proof chambers during August to October 2020 on potted Hibiscus rosa sinensis plants and on a preinfested Shami plant (used as reservoir of live mealybugs as well as secondary experimental plant) present in the college premises. A total of 5 potted Hibiscus plants were taken inside insectproof chambers of which one potted plant was kept as control plant while rest were taken as experimental plants for different herbal pesticide experiments.

\section{Screening of Suitable Herbal Pesticide:}

Four plants were screened for the management of striped mealybug (Ferrisia virgata) that were Clerodendron sp., Cymbopogon citratus, Pongamia pinnata and Azadirachta indica. The Azadirachta indica, Clerodendron sp. and Pongamia pinnata were screened because of their abundance and already known to have some insecticidal properties (Tripathi et al., 2012; Arya, 2019). The Cymbopogon citratus was taken as experimental herbal pesticide plant as it was not seen infested with the mealybugs as well as it contains some insecticidal and some insect repellent properties (Idibie et al., 2018) which may be used to repel the mealybug symbiotic associates i.e. fire ants.

\section{Preparation of Herbal pesticides}

100 gram green leaves of each experimental plants (Clerodendron sp., Cymbopogon citratus and Pongamia pinnata) were taken and thoroughly washed with a mild soap and then cleaned with tap water twice and were kept in 500 $\mathrm{ml}$ double distilled water overnight separately. Now the green leaves of every plant were grinded using the same water in which it was soaked overnight. All aqueous extracts were filtered separately and distilled water was added to make final volume $700 \mathrm{ml}$. Now absolute alcohol was added to each extract in order to make the final volume $1000 \mathrm{ml} .30$ per cent ethyl alcohol was used because there is a thick waxy layer over the mealybugs and water cannot penetrate it. So it cannot carry the active compounds of herbal pesticide, while the ethyl alcohol has a good property to dissolve wax and penetrate deep carrying the herbal active compounds, insecticidal factors. 
Primary foliar spray over mealybugs infected plant

$100 \mathrm{ml}$ spray of each herbal pesticide was used on infested Shami plant and on all four potted Hibiscus plants, while the fifth potted Hibiscus plant was kept as control. The Clerodendron and Pongamia pinnata extracts were found ineffective against mealybugs while the Azadirachta indica and Cymbopogon both were found partially effective however Neem extract spray in 10 percent concentration caused some blight like symptoms over Shami plant leaves and caused death of leaves (Fig.2).

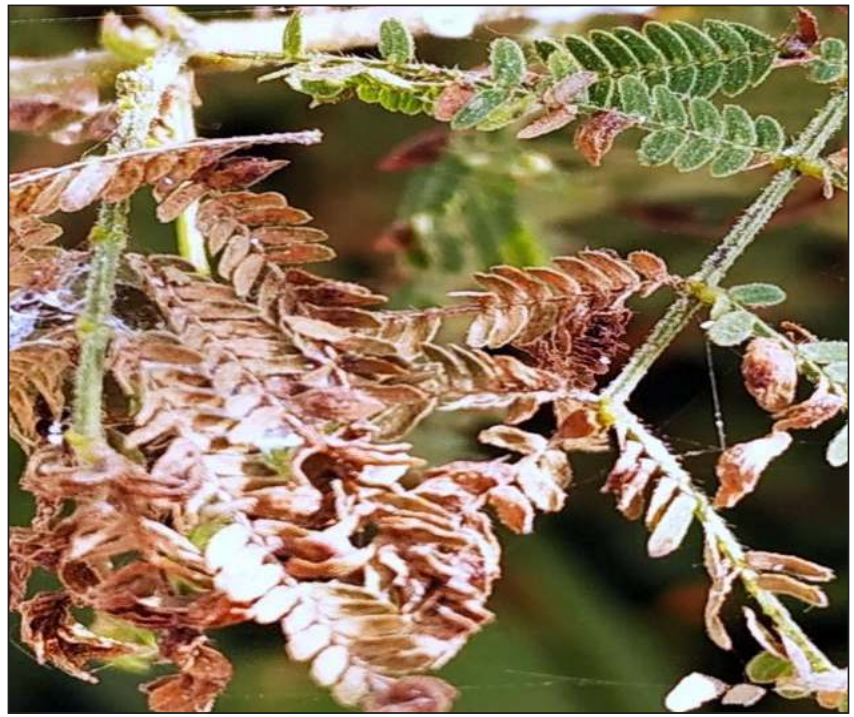

Fig.2: Blighted Shami plant leaves after Neem extract spray.

Now it is the primary finding that Cymbopogon extract may be better herbal pesticide to control the striped mealybugs as found in table-1
Standardization of most effective pesticide concentration of Cymbopogon leaves

The extract of Cymbopogon was found most suitable but it is now to be standardized for most effective and safe concentration. The 30 percent ethanolic extract of plant material concentration 10 percent, 15 percent, 20 percent, 25 percent and 30 percent were tested on experimental plants. The concentration of 25 percent was found safe and effective with no recurrence of mealybugs while there was recurrence up to the concentrations of 20 percent (Fig.3 \& Fig.4). The 30 percent concentration of plant extract was found somewhat harmful as it causes some tiny spots over potted Hibiscus leaves (Table 2).

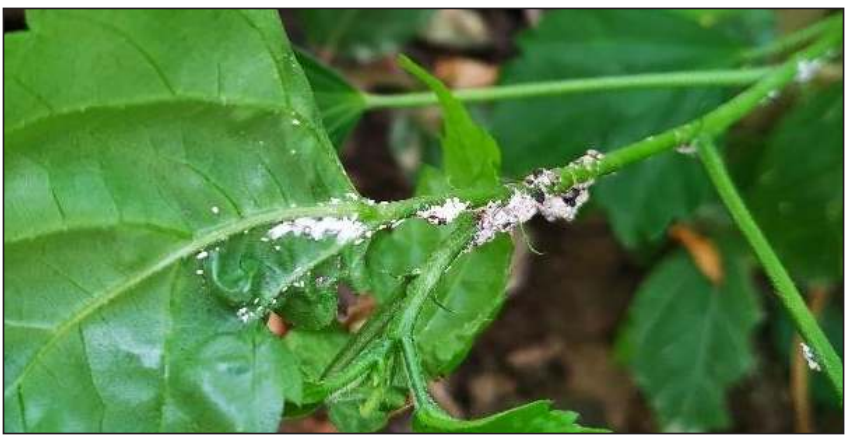

Fig.3: Striped mealy bug infected Hibiscus twig.

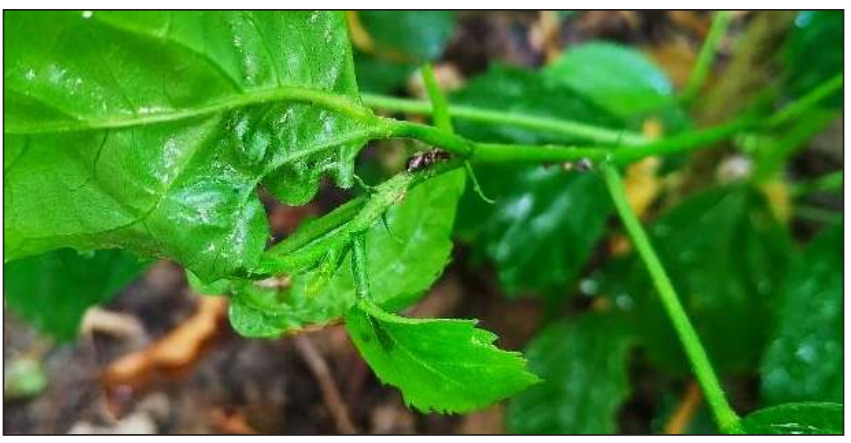

Fig.4: Striped mealybug controlled Hibiscus twig.

Table 1: Effectiveness of leaves extracts (Biopesticides) on Ferrisia virgata.

\begin{tabular}{|l|l|l|l|}
\hline S.N. & Experimental Plant & Extract of leaves & Effectiveness on stripped mealybugs \\
\hline 1. & Potted Hibiscus-1 & Neem & Partially effective \\
\hline 2. & Potted Hibiscus-2 & Clerodendron & Non effective \\
\hline 3. & Potted Hibiscus-3 & Pongamia pinnata & Non effective \\
\hline 4. & Potted Hibiscus-4 & Cymbopogon & Fully effective \\
\hline
\end{tabular}

Table 2. Effect of Cymbopogon on adult mealy bugs.

\begin{tabular}{|l|c|c|c|c|c|}
\hline \multirow{2}{*}{$\begin{array}{l}\text { Cymbopogon } \\
\text { leaves extract }\end{array}$} & \multicolumn{5}{|c|}{ Concentrations of extract (\%) } \\
\cline { 2 - 6 } & $\mathbf{1 0}$ & $\mathbf{1 5}$ & $\mathbf{2 0}$ & $\mathbf{2 5}$ & $\mathbf{3 0}$ \\
\hline $\begin{array}{l}\text { Effectiveness on } \\
\text { Mealybug (\%) }\end{array}$ & $20.12 \pm 1.27$ & $47.13 \pm 1.58$ & $79.08 \pm 1.11$ & $95.97 \pm 2.10$ & $\begin{array}{l}\text { Adverse effect on } \\
\text { experimental plant }\end{array}$ \\
\hline
\end{tabular}




\section{RESULTS AND DISCUSSIONS}

The 25 percent concentration of Cymbopogon leaf extract was found as a most effective eco-friendly management tool and safe herbal pesticide having no harmful effect over either of the experimental plants or over the other plants.

The very common and harmful wax coated striped mealybugs (Ferrisia virgata) are very tough to control in fruit orchards and flower crops. Normally chemical pesticides are used to manage these annoying tiny insects but they are partially effective as they can't break the symbiotic relationship between mealybugs and fire ants (Bhat etal., 2003).

During this experiment, four plants having known for some insecticidal and insect repellent properties were tested and the most appropriate was found as Cymbopogon sp. Neem extract was also found effective but over some plants such as Shami plant it has adverse effects (leaf blight) in effective concentrations.

The 25 percent concentration of Cymbopogon leaves extract was found most effective for the successful control of striped mealybugs (Ferrisia virgata) and there was no recurrence. The fire ants also hesitate to visit the herbal pesticide sprayed twigs and branches of the experimental plants due to its insect repellent properties thereby ceasing the recurrence of the mealybug's infestation.

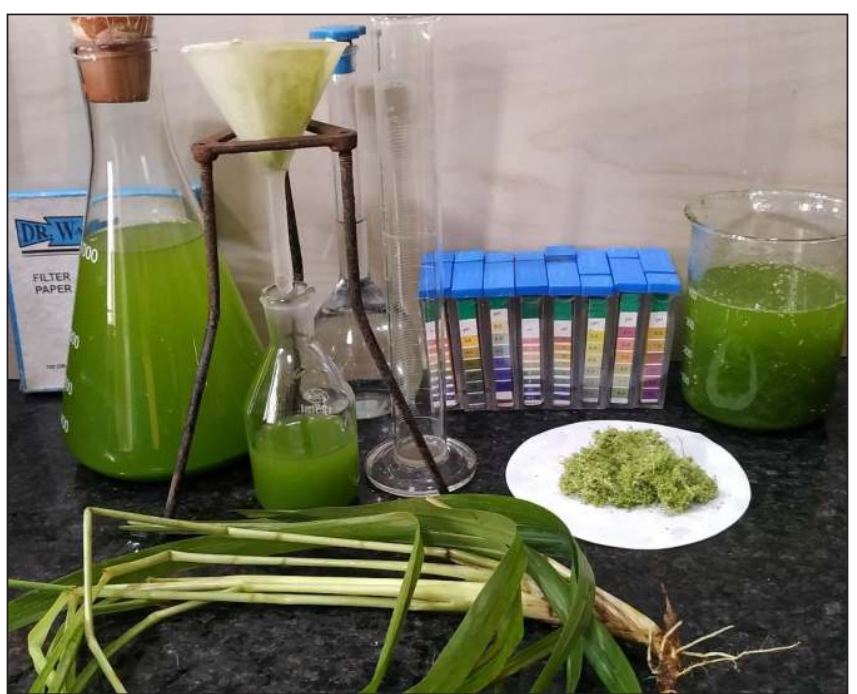

Fig. 5: Herbal pesticide leaves extraction of Cymbopogon sp.
For large scale application of Cymbopogon herbal insecticide (Fig. 5) one per cent mild soap should be added as emulsifying agent to make the sprays more evenly concentrated however in the present experiment no mild soap was added to avoid deviation from the real effectiveness of herbal actives of plants.

The striped mealybugs (Ferrisia virgata) infestation over Hibiscus and Shami plants were successfully controlled by using 25 percent concentration of Cymbopogon leaf extract (by weight) in a costeffective and eco-friendly manner.

\section{ACKNOWLEDGMENTS}

Author is thankful to all the staff members of Zoology Department, MLK P.G. College, Balrampur (U.P.) for their continuous support in the present study.

\section{REFERENCES}

1. Ammar E., Awadallah K. and Rashad A. (1979). Ecological studies on Ferrisia virgata CKLL. on Acalypha shrubs in Dokki, Giza (Homoptera, Pseudococcidae). Deutsche Entomologische Zeitschrift. 26: 207-213.

2. Arya S. (2019). Evaluation of Bio efficacy of Azadirachta indica and Mentha piperita extract against Papilio demoleus L. on Citrus crop. International Journal of Biological Innovations. 1(2): 87-89. https:// doi.org/ 10.46505/IJBI.2019.1210

3. Ashok K. V. (2017). Necessity of Ecological Balance for Widespread Biodiversity. Indian Journal of Biology. 4(2): 158-160. http:// dx.doi.org/10.21088/ijb.2394.1391.4217.15.

4. Ashok K. V. (2018). Ecological Balance: An Indispensable Need for Human Survival. Journal of Experimental Zoology, India. 21 (1): 407-409.

5. Bhat A., Devasahayam S., Sarma Y. and Pant R. (2003). Association of a Badnavirus in black pepper (Piper nigrum L.) transmitted by mealybug (Ferrisia virgata) in India. Current Science. 84: 1547-1550.

6. Cheng S., Zeng Ling and YijuanXu (2015). Mutualism Between Fire Ants and Mealybugs 
Reduces Lady Beetle Predation. J. Econ. Entomol. 108(4): 1560-1569. 10.1093/ jee/tov117

7. Dreistadt S. H. (2001). Integrated Pest Management for Floriculture and Nurseries (vol 3402). UCANR Publications. 422p.

8. Franco J. C., Zada A. and Mendel Z.(2009). Novel approaches for the management of mealybug pests. Biorational Control of Arthropod Pests. Springer, London. 233-278.

9. Ferris G. F. (1950).Atlas of the Scale Insects of North America, (v.5): The Pseudococcidae (Part I). Stanford University Press, California, USA. 278p.

10. Idibie C.A., Nwaokobia K., Ogboru R. O. and Omoregie P. O. (2018). The Insecticidal Properties of Cymbopogan, Citratus and Mentha piperita L; Evaluation Studies. International Journal of Current Research. 10(5):68908-68912.

11. Kaur G. and Mishra B. K. P. (2019). Histopathological changes in Liver of fish Channa punctatus exposed to sub lethal concentration of Hybrid Pesticide. Int. Journal of Biological Innovations. 1(2): 83-86. https://doi.org/ 10.46505/IJBI.2019.1209

12. Kaydan M. B. and Gullan P. J. (2012). A taxonomic revision of the mealybug genus Ferrisia Fullaway (Hemiptera:
Pseudococcidae), with descriptions of eight new species and a new genus. Zootaxa. 3543 (1):1-65.

13. Prakash S. and Verma A. K. (2014). Effect of Organophosphorus Pesticide (Chlorpyrifos) on the Haematology of Heteropneustes fossilis (Bloch). International Journal of Fauna and Biological Studies. 1(5): 95-98.

14. Prakash S. and Verma A. K. (2020). Effect of organophosphorus pesticides on Biomolecules of fresh water fish, Heteropneustes fossilis (Bloch). Indian Journal of Biology. 7(2): 65-69. http:// dx.doi.org/10.21088/ijb.2394.1391.7220.8

15. Tripathi A., Singh N., Misra M., Dwivedi H. D. and Dubey N. K. (2012). An earth-friendly herbal pesticide from Pongamia pinnata L. Current Botany. 3(2): 01-02.

16. Verma A.K. and Prakash S. (2018). Haematotoxicity of Phorate, an Organophosphorous pesticide on a Freshwater Fish, Channa punctatus (Bloch). International Journal on Agricultural Sciences. 9 (2): 117120.

17. Williams D. J. and Watson G. W. (1988). The Scale Insects of the Tropical South Pacific Region. part-2: The Mealybugs (Pseudococcidae). CAB International Oxon, UK. 260p. 